\title{
GLOBAL EXISTENCE AND BLOW-UP FOR NONAUTONOMOUS SYSTEMS WITH NON-LOCAL SYMMETRIC GENERATORS AND DIRICHLET CONDITIONS
}

\section{AROLDO PÉREZ}

Abstract. We study a semilinear system of the form

$$
\begin{aligned}
\frac{\partial u_{i}(t, x)}{\partial t} & =k_{i}(t) \mathscr{A}_{i} u_{i}(t, x)+u_{i^{\prime}}^{\beta_{i}}(t, x), \quad t>0, \quad x \in D, \\
u_{i}(0, x) & =f_{i}(x), \quad x \in D,\left.\quad u_{i}\right|_{D^{c}} \equiv 0,
\end{aligned}
$$

where $D \subset \mathbb{R}^{d}$ is a bounded open domain, $k_{i}:[0, \infty) \rightarrow[0, \infty)$ is continuous, $\mathscr{A}_{i}$ is the infinitesimal generator of a symmetric jump-type process $Z_{i} \equiv\left\{Z_{i}(t)\right\}_{t \geqslant 0}, \beta_{i}>1, i \in\{1,2\}$ and $i^{\prime}=3-i$. Under some assumptions on the infinitesimal generator $\mathscr{A}_{i}^{D}$ of the subprocess $Z_{i}$ killed upon leaving $D, i=1,2$, we give sufficient conditions for global existence or finite-time blow-up of the positive mild solutions of our system. This paper can be considered as a continuation of the article [16].

Mathematics subject classification (2010): 60J75, 60G52, 35B35, 35K57.

Keywords and phrases: semilinear nonautonomous equations, Dirichlet problem, ultracontractive semigroup, Markov evolution systems, finite-time blow up.

\section{REFERENCES}

[1] Z-Q. Chen, P. KIM AND R. Song, Sharp heat kernel estimates for relativistic stable processes in open sets, Ann. Probab., 40, 1 (2012), 213-244.

[2] Z-Q. Chen, P. KIM AND R. Song, Dirichlet Heat Kernel Estimates for $\Delta^{\frac{\alpha}{2}}+\Delta^{\frac{\beta}{2}}$, Illinois J. Math., 54, 4 (2010), 1357-1392.

[3] Z-Q. Chen, P. Kim And R. Song, Heat kernel estimates for the Dirichlet fractional Laplacian, J. Eur. Math. Soc., 12 (2010), 1307-1329.

[4] Z-Q. Chen And T. Kumagai, Heat kernel estimates for jump processes of mixed types on metric measure spaces, Probab. Theory Relat. Fields, 140 (2008), 277-317.

[5] K.Deng And H. A. Levine, The role of critical exponents in blow-up theorems: the sequel, J. Math. Anal. Appl., 243, 1 (2000), 85-126.

[6] M. EsCOBEDO AND M. A. HeRRERo, Boundedness and blow up for a semilinear reaction-fiffusion system, J. Differential Equations, 89, 1 (1991), 176-202.

[7] H. FujITA, On some nonexistence and nonuniqueness theorems for nonlinear parabolic equations, Nonlinear Functional Analysis (Proc. Sympos. Pure Math., Vol. XVIII, Part 1, Chicago, Ill., 1968), Amer. Math. Soc., Providence, R. I. (1970), 105-113.

[8] V. A. Galaktionov, S. P. Kurdyumov AND A. A. SAMARS KiI, A parabolic system of quasilinear equations. I., Differential Equations, 19, 12 (1983), 1558-1574.

[9] V. A. Galaktionov, S. P. KuRdyumov AND A. A. SAMARS KiI, A parabolic system of quasilinear equations. II., Differential Equations, 21, 9 (1985), 1049-1062.

[10] T. GrZYWNY, Intrinsic ultracontractivity for Lévy processes, Prob. Math. Stat., 28, 1 (2008), 91-106.

[11] M. Guedda And M. Kirane, Critically for some evolution equations, Differential Equations, 37, 4 (2001), 540-550. 
[12] S. KeRBAL, Non-existence of global solutions to systems of non-autonomous nonlinear parabolic equations, Commun. Appl. Anal., 14, 2 (2010), 203-212.

[13] M. Kirane, Y. LASKRI AND N. TATAR, Critical exponentes of Fujita type for certain evolution equations and systems with spatio-temporal fractional derivatives, J. Math. Anal. Appl., 312 (2005), 488-501.

[14] M. Kirane AND M. QAFSAOUi, Global nonexistence for the Cauchy problem of some nonlinear reaction-diffusion systems, J. Math. Anal. Appl., 268 (2002), 217-243.

[15] E. T. Kolkovska, J. A. López-Mimbela And A. PÉrez, Blow-up and life span bounds for a reaction-diffusion equation with a time-dependent generator, Elec. J. Diff. Equations, 2008, 10 (2008), $1-18$.

[16] J. A. López-Mimbela AND A. PÉrez, Global and nonglobal solutions of a system of nonautonomous semilinear equations with ultracontractive Lévy generators, J. Math. Anal. Appl., 423, 1 (2015), 720-733.

[17] J. A. López-Mimbela And A. Pérez, Finite time blow up and stability of a semilinear equation with a time dependent Lévy generator, Stoch. Models, 22, 4 (2006), 735-752.

[18] J. A. LóPEZ-Mimbela AND A. TORRES, Intrinsic ultracontractivity and blowup of a semilinear Dirichlet boundary value problem, Aportaciones Matemáticas, Modelos Estocásticos, 14, Sociedad Matemática Mexicana, (1998), 283-290.

[19] A. PÉREZ, A blow up condition for a nonautonomous semilinear system, Electron. J. Diff. Eqns., 2006, 94 (2006), 1-8.

[20] A. PÉReZ AND J. Villa, A note on blow-up of nonlinear integral equation, Bull. Belg. Math. Soc.Simon Stevin, 17 (2010), 891-897.

[21] M. RYZnAR, Estimates of Green function for relativistic $\alpha$-stable process, Potential Anal., 17 (2002), $1-23$.

[22] Y. UDA, The critical exponent for a weakly coupled system of the generalized Fujita type reactiondiffusion equations, Z. ang. Math. Phys., 46 (1995), 366-383.

[23] J. Villa-Morales, Blow up of mild solutions of a system of partial differential equations with distinct fractional diffusions, Electron. J. Diff. Eqns., 2014, 41 (2014), 1-9. 